The Role of Children's Education for the Mental Health of Aging Migrants in Europe

Dr Albert Sabater and Professor Elspeth Graham, University of St Andrews

$\underline{\text { Correspondence details }}$

School of Geography \& Geosciences, Department of Geography and Sustainable Development, University of St Andrews, St Andrews, Scotland, UK

Email: albert.sabater@st-andrews.ac.uk 


\section{The Role of Children's Education for the Mental Health of Aging Migrants in Europe}

\section{Abstract}

In this study, using SHARE data we examined whether adult children's education is associated with depressive symptoms (EURO-D caseness) for older immigrants and non-immigrants in Europe. After controlling for possible confounders, we found that the education of adult children has independent effects on the mental health of their parents, and that having children with upper secondary or tertiary levels of education significantly lessen the odds of immigrants experiencing depressive symptoms. Furthermore, regular contact between parents and their adult children exerts a positive influence as well as amplifying the relationship between children's education and mental health. Taken together, the results demonstrate that, were it not for family social capital, older immigrants might experience much worse mental health outcomes.

Keywords: mental health, aging migrants, adult children, education, Europe

\section{Introduction}

There are inevitable concerns over the well-being of significant numbers of older migrants as well as a desire to maximize the opportunities afforded by the healthy aging of people who moved into, and across, Europe over the past fifty years (Warnes \& Williams, 2006). As a large number of first generation immigrants are currently approaching retirement age in many European countries, interest has grown in providing further understanding of the relationship between the prevalence of depression and immigrant status. While several studies suggest that mental ill health is higher for immigrant groups in a substantial part of European countries (Carta, Bernal, Hardoy \& Haro-Abad, 2005; Tinghög, Hemmingsson \& Lundberg, 2007), others suggest that immigrant status seems irrelevant once other risk factors such as socioeconomic conditions and the experience of discrimination are accounted for (Missinne \& Bracke, 2012). However, as Ladin \& Reinhold (2013) emphazised, most studies have documented this relationship among working-age migrants predominantly, while older migrants have yet to receive much attention. As a result of this limited view, much less is known about the specific dimensions of social support at older ages such as the role of children's education for mental 
health of aging migrants in Europe. For many older European parents, ties with adult children represent a major element of their social networks as well as a predominant potential source of emotional and household support (Buber \& Engelhardt, 2008). However, while it has long been recognised by social exchange theory that the rearing of children and intergenerational transfers are seen as major investments in virtually all societies (Astone, Nathanson, Schoen \& Kim, 1999), to the best of our knowledge the association between children's education and the mental health of aging migrants has not been tested.

Using representative and comparable survey data across from the Survey of Health, Aging and Retirement in Europe (SHARE) across eight 'old' immigration countries, we examined the impact of children's education on the mental health of their parents using the EURO-D index. Building on earlier seminal works on "upward" health transfers (i.e. from children to parents) in Europe (Torssander, 2013; Sabater \& Graham, 2016), this study addresses the following research questions: (1) Does the educational attainment of adult children have differential effects on the mental health of older migrants? (2) Does the educational attainment of adult children have a stronger influence on the mental health of older migrants with lower education than their children?

\section{Integrating Children's Education into Existing Conceptual Models}

There is a long tradition of studies on the mental health consequences of migration focusing on the experience of migration as a stressful event and the notion that first generation immigrants are necessarily disadvantaged due to migration stressors such as lower income and higher job insecurity as well as loss of social status and limited social and emotional support (Berry, 1997; Alegria, Canino, Shrout, Woo, Duan et al., 2008; Schwarzer \& Schulz, 2012). Because immigrants disproportionately face hardships, a social-stress model predicts that immigrants are at higher risk for depressive symptoms, with a general view that the effects of migration may only be mitigated by the course of time or acculturation, the latter often being measured by time since immigration, citizenship status or age at migration (Berry, 1997).

While the migration stress theory underlines the emotional distress and psychiatric disorders resulting from migration, another seemingly divergent framework - the healthy migrant 
hypothesis - suggests that first-generation immigrants may be more resilient and healthier than the native-born population because of the selective migration of healthy individuals (Burnam, Hough, Karno, Escobar \& Telles, 1987; Gong, Xu, Fujishiro \& Takeuchi, 2011). As Ladin \& Reinhold (2013) highlight, one might assume lower rates of depression among immigrants given the connection between physical and mental health. However, research has shown that the importance of selection effects at younger ages leading to what is known as the "healthy migrant effect" decrease with length of residence in the country of destination (Stronks, 2003), with illhealth being more marked with increasing age amongst ethnic minorities (Nazroo, 2006).

Moreover, the superior physical health advantage of immigrants may be more or less important depending on two major aspects (Mirowsky and Ross, 1980). From a minority-status perspective, immigrants tend to occupy disadvantaged positions in the social structure, and the chronic social stressors associated with these positions produce distress. For instance, recent research showed that precarious socioeconomic conditions and the experience of discrimination are of particular importance in explaining the elevated levels of depressive symptoms among immigrants in Europe (Missinne \& Bracke, 2012). Although the (mental) health status of some groups is less sensitive to their socioeconomic circumstances than others (Nazroo, 2003), it seems clear that older migrants are at a uniquely high risk of experiencing depression as they share the same burden of difficulties as any aging person (Uhlenberg \& Riley, 2000) in addition to other socially disadvantaged conditions such as lower socioeconomic status, lack of personal networks and language knowledge (Blazer, 2003). From an ethnic-cultural perspective, it is also expected that differences in beliefs, values, and patterns of living produce different distress levels. Although research has also placed a great deal of emphasis on the meaning of illness among ethnic and immigrant groups, implying different perceptions on the combined physical and psychological health, the existing evidence is rather inconclusive with critics' main concern being that such explanations obscure the impact of structural factors on immigrant health disparities (Viruell-Fuentes, Miranda \& Abdulrahim, 2012).

The social stratification of aging and mental health clearly presents both an intellectual challenge and an opportunity to broaden current analyzes emphasizing individual effects rather than multigenerational family perspectives. There are many aspects of intergenerational solidarity or 
"linked lives" that could have repercussions for the mental health of both older native-born populations and aging migrants. With strong intergenerational relations and educational expansion $^{1}$, it is expected that social relationships within, and outside, the household have the potential to create synergistic effects, including the promotion of (mental) health among older adults (Seeman, 2000).

Although the motivation of adult children to provide support to their older parents is partially rooted in earlier family experiences, it is also guided by an implicit social contract that ensures long-term reciprocity (Silverstein, Gans \& Yang, 2006). Buber \& Engelhardt (2008) suggested that children can impact on the mental health of their parents through social effects as well as selection effects related to parenthood. In other words, while poor mental health is usually found among groups with weak social support (Lehtinen, Sohlman \& Kovess-Masfety, 2005), people with good mental health and favourable socioeconomic characteristics are more likely to marry and have children. In this sense, it may be argued that without information on pre-existing psychological states, the possibility that people with better psychological health are selected into marriage and the most distressed remain unmarried; however, self-selection would not account for the overall differences (Mastekaasa, 1992).

Why more parents of well-educated children than parents of less well-educated adult children live without depression symptoms is not yet fully established. Although the advantages of having children with important resources extend beyond the health benefits to parents, explanations that are directly related to the value of education for mental health are possible and may constitute a core component of family support in the broader context of intergenerational exchanges. Therefore, congruent with the life-course perspective, the education of children can act as a family-level resource even in contexts of increased geographical separation between adult children and parents, thus responding to the available resources and needs associated with an individual's life course status. This study hypothesises that upward intergenerational transfers occur among migrants in Europe, with mental health benefits for older migrants with welleducated adult children. 


\section{Potential Pathways for Upward Intergenerational Health Transfers}

Theories about the relationships between social networks and health suggest various pathways through which social contacts may influence health (Berkman \& Glass, 2000). According to Torssander (2013: 638) "three of these pathways are potentially relevant for child-to-parent transmission: provision of social support, social influence, and access to resources". The first pathway - social support - includes various types of support, such as emotional, instrumental, and informational support. The second pathway - social influence - is another possible causal mechanism strongly linked to well-being. The third pathway - access to resources - traditionally refers to material resources, although it may also relate to the nonmaterial returns of the education of adult children in terms of information support. These mechanisms are not mutually exclusive and support the idea that having multiple resources, including those that originate from adult children's education, makes health outcomes such as depression less dependent on individual characteristics. In other words, resources from others can be used to decrease one's own depression (Mirowsky, Ross \& Reynolds, 2000): Parents can fill the gap if children are present, hence the less there is of one resource, the more important another becomes. Since poorly educated parents may not possess the resources necessary to achieve their goals, producing a sense of powerlessness, fatalism, and helplessness (Wheaton, 1980), they may be able to share the nonmaterial returns of education of close others such as adult children (Cutler \& Lleras-Muney, 2010) and develop competence on many levels, giving them the ability and motivation to share and control their lives (Ross \& Mirowsky, 1989). In addition, the value of the education of adult children may also be relevant in multiplicative terms, which implies that highly educated parents may actually obtain larger emotional benefits from the higher levels of education of their children. Thus, advantaged groups stand to gain most from the resources they have at their disposal (Ross \& Mirowsky, 2006).

Another way of thinking about potential upward health transfers is via direct and indirect effects (Friedman \& Mare, 2014). In other words, while children may directly affect the mental health of parents by consciously providing better access to information and care, they may also affect the mental health of parents through health "spillover" or "contagion" effects. In practical terms, the latter means that the exposure of parents to their educated children's health behaviours and lifestyles may influence them to adopt healthier behaviours of their own. This view would be in 
keeping with social cognitive theory (Bandura, 1986), which highlights how individuals learn behaviours by observing the behaviours of others, especially if the person being observed is respected, powerful or has valuable information. Of course, not all children are in a similar position. Children who themselves require assistance because of poor health or limited financial resources are less likely to help their parents, whereas children with more education who have more resources and flexible jobs are more likely to help and/or provide care (McGarry, 1998).

While it is well-established that adult children can provide a great deal of personal care - and this includes assisting in daily activities as well as providing social interaction and recreation - they also bring considerable financial, knowledge, and management resources into decisions about the timing and quality of health care and subsequent actions (Friedman \& Mare, 2014). There are good reasons to presume that the influence of the education of adult children on parental mental health can be important, as the pooling of material and information resources is likely to translate into a variety of well-being-related functions for their parents. Within this context, who share similar values about family obligations are expected to have a closer relationship and support each other more than families with a lower value of consensus according to the intergenerational solidarity model (Albert \& Ferring, 2013). Moreover, the existence of a basic opportunity structure for intergenerational interaction, which is often measured in terms of contact and proximity, is fundamental to the reciprocity in parent-child relationships (Bengtson, 2001).

In sum, although the possible pathways from adult children's education to parental mental health span a wide range of economic, psychological, and sociological factors, it is widely acknowledged that higher education may be an indicator of knowledge, access to economic resources, propensity to adopt health-enhancing lifestyles (House, Kessler, Herzog, Mero, Kinney et al., 1994), and a sense of control which helps individuals achieve emotional wellbeing (Ross \& Mirowsky, 2006). This paper attempts to measure these effects in the context of migration research. Nonetheless, the current study does not attempt to disentangle the causal relation between the educational attainment of adult children and the mental health of older migrants. Rather, it aims to document associations of own education and that of adult children with depression among the native and foreign-born population aged 50 and over in "old" immigration countries in Europe. 


\section{Data and Methods}

The study is based on the baseline study (year 2004) of the Survey of Health, Aging and Retirement in Europe (SHARE), which includes detailed cross-national information on health, well-being, and economic circumstances of noninstitutionalized people aged 50 and older (for a detailed description of the data, methodology and results, see Börsch-Supan, 2013; BörschSupan \& Jürges, 2005; Börsch-Supan et al., 2005). Analyzes are carried out using data for 8 "old" immigration countries: Austria, Belgium, Denmark, France, Germany, The Netherlands, Sweden, and Switzerland. Focusing on these "old" immigration countries is important to avoid substantial heterogeneity among migrants across countries, particularly with respect to the more recent migration processes of retirement migration (e.g. southern Europe), and as a consequence of Eastern European transformation states ${ }^{2}$. As shown in Table 1, the countries with the larger share of older immigrants are Germany (19.6\%), Switzerland (14.7\%) and France (13.5\%), whereas the origin countries most represented in our sample (not shown here) include Germany (14.9\%), Italy (7.1\%), Poland (6.4\%) and Algeria (4.9\%). This evidence is consistent with the major migration movements since 1945, which include ethnic Germans from the states of the former Soviet Union and other former Eastern Bloc states, "temporary" workers (plus their families) during the "guest-worker" programs as well as migrants from colonial legacies. Our total sample consists of 10,518 individuals (9,489 native-born and 1,029 foreign-born), after excluding 1,784 respondents without children (1,605 native-born and 179 foreign-born).

[Table 1 about here]

Methodologically, the present study employs a multilevel logit model to assess the association between children's education and the odds of experiencing mental ill-health (depressive symptomatology) among older migrants after adjusting for relevant confounders. The analysis is undertaken at two distinct levels: respondents (level-1 units) and countries (level-2 units). We run this model using the gllamm Stata command, which allows us to estimate a random coefficient model that relaxes the assumption that the effect of children's education and other covariates are the same for all countries under consideration. Since the small number of observations in the existing dataset precludes a full investigation of national differences, the multilevel approach 
allows us to incorporate the country-level characteristics into our analysis. The latter aspect is important not only due to cross-national differences in relation to immigration policies, health care systems and macroeconomic conditions, but also because there might be significant variation in the levels of intergenerational help and care across countries in Europe (Brandt et al., 2009). Our modelling strategy also includes fixed effects for the geographical origins of immigrant groups (see Table 2) as an effective way to control for differences among foreignborn populations. Given that spouses of respondents were also interviewed, robust standard errors are estimated to adjust for clustering of respondents within households.

[Table 2 about here]

The central variable in our study is the EURO-D symptom scale (Prince et al., 1999), which is a validated measure of mental health ranging from 0 to 12 and covering the following items: depressed mood, pessimism, suicidality, guilt, sleep, interest, irritability, appetite, fatigue, concentration, enjoyment and tearfulness. For our dependent variable, the current analysis uses a dichotomous outcome, which was determined in the current analysis as having received a scored above the clinical cut off point of 3 (Dewey \& Prince, 2005). In other words, reporting four or more depressive symptoms out of the list of 12 items mentioned above is an indicator for being clinically depressed (EURO-D caseness) ${ }^{3}$. As noted in other studies (e.g. Ladin \& Reinhold, 2013), a dichotomised measure is useful both because it best aligns with a clinical outcome, and because it allows for comparability with previous studies using a similar analytical approach.

In our analysis, immigration status, educational attainment of adult children and frequency of contact between parents and noncoresiding adult children are the primary independent variables. In SHARE, immigrants were identified using information on whether respondents were born outside their country of residence. Since they also reported the year in which they arrived, we computed the age at migration of foreign-born respondents (see Table 3), which is estimated to be 22.5 years $(S D=15.4)$. For the analyzes, however, we employed a categorical variable to control for their age-specific characteristics at migration as most immigrants arrived after finishing school, aged 16 to 49 (59.1\%), but other immigrants arrived under age 16 (33.4\%) or even at older ages, $50+$ years $(7.5 \%)$. Our sample also reveals that nearly three-quarters of 
immigrants (74.6\%) have the citizenship of the country of residence, which is considered to be an important element to reduce stigma and discrimination of people with mental illness (Thornicroft, Brohan, Kassam \& Lewis-Holmes, 2008).

\section{[Table 3 about here]}

The availability of information on the respondent's migration status, own socioeconomic status and the characteristics of their children, including educational attainment, makes SHARE a valuable dataset for examining the relationship between the education of adult children and their parents' mental health. The measure of children's education is obtained from the highest level of educational attainment and classified into compulsory (primary and lower secondary education) and non-compulsory levels (upper secondary and tertiary). Since information on education is available for up to four children, several constructions of adult children's education have been tested, including (1) whether any child has tertiary education, (2) the average years of educational attainment of all children, and (3) the oldest child with the highest level of education, aged at least 25. Although the three constructions of education fit the data equally well, we decided to employ the last one based on the notion that there is a larger benefit from the first child than the later children (Christiansen, 2014). In doing so, we assume that the mental health of an older adult is most strongly influenced by the oldest child with the highest educational attainment as she or he is likely to have the greatest availability of resources (Torssander, 2013; Sabater \& Graham, 2016). Moreover, in order to evaluate whether the educational attainment of adult children has a stronger influence on the mental health of older parents with lower education than their children, we devised a measure of educational differences with two categories for parents and their adult children (primary/lower secondary, and upper secondary/tertiary).

While the question about contact between parents and adult children does not distinguish face-toface, telephone, or other modes of contact, it allows for the measurement of frequency of contact during the past year (i.e. 12 months preceding the interview) between parent-child pairs. Following a similar approach to Hank (2007), we collapsed the original set of seven answer categories into two groups: daily or weekly and less than weekly. As with the measure of education, frequency of contact was taken from the oldest child with the highest level of 
education, aged at least 25. Coresident parent-child pairs were excluded from the analysis of contacts because the respective question is not asked when parent and child live in the same household.

Our modelling strategy included the following steps: first, we examined change in the immigration coefficient of the multilevel logistic regressions after including information on respondents' characteristics that were found to have an effect on mental health, including (1) demographic factors (immigrant status, age, and sex); (2) physical health (chronic diseases and limitations in activities of daily living); (3) socioeconomic status (educational attainment of respondent and his/her partner as well as household income ${ }^{4}$ ); (4) social participation (involvement in charity, education or training, sport or social club, religious organisation, political/community activities); and (5) family social capital/support (number of children, children's education, and frequency of contact between children and parents). The analysis of change in the immigration coefficient indicates that the given independent variables explain some variation in the effect of immigration. Second, we conduct separate analysis with all the explanatory variables for nonimmigrants and immigrants, including citizenship, age at migration and geographical origin of immigrants as additional controls for the latter group. This analysis highlights whether the education of adult children has an independent effect on parental mental health. Finally, we repeat the analyzes using a derived measure of the difference between the educational attainment of child and parent in order to gain further understanding of this relationship.

\section{Results}

\section{Descriptive Findings}

Table 3 shows the characteristics of the study sample. The mean age among nonimmigrants was 66.2 years and 66.5 years for immigrants. The sample adequately reflects the size of populations by gender born in 1954 or earlier in the 8 "old" immigration countries participating in the first wave of SHARE, with more female than male respondents for nonimmigrants (53.7\% vs. $46.3 \%$ ) and immigrants (55\% vs. $45 \%$ ). As expected, immigrants have fewer economic resources (household income) than comparable nonimmigrants. It is also evident that many respondents only had compulsory education, with similar shares found among nonimmigrants (44.8\%) and 
immigrants $(44.1 \%)$. In contrast, our sample suggests that the majority of adult children had attained noncompulsory education, although there are some small differences between nonimmigrants $(87.3 \%)$ and immigrants $(85.2 \%)$. Another way to assess the potential for upward intergenerational transfers is to show the differences of adult children's educational attainment by parent's own educational attainment (see cross-tabulation in Table 4$)^{5}$.

[Table 4 about here]

Although the results suggest that there is a correlation between the educational level of parents and their adult children, the results also indicate that there is a widespread distribution of respondents with children who have different levels of education. For instance, for immigrant respondents with lower secondary education, an average of $29.1 \%$ of their children have tertiary education, 55.2\% have upper secondary, $14.5 \%$ lower secondary and $1.2 \%$ have primary education. Meanwhile, for nonimmigrant respondents with upper secondary education, an average of $41.7 \%$ of their children have tertiary education, $52.9 \%$ have upper secondary, $5.1 \%$ have lower secondary and $0.3 \%$ have primary education. Of course, although this profile is important for the expectation regarding the impact of children's education on their parents' mental health, there are other factors that can play a crucial role. Perhaps most importantly, frequency of contact between parents and noncoresiding adult children appears to be relatively widespread as demonstrated by the fact that more than three-quarters of nonimmigrants $(78.7 \%)$ and immigrants $(75.6 \%)$ have regular contact (i.e. daily or weekly) with their adult children. Other important background factors such as the availability of spouses/partners and their educational attainment are also controlled to account for marital selection effects and further availability of socioeconomic resources.

\section{Multivariate results}

In order to examine change in the immigration coefficient, Table 5 reports five explanatory pathways underlying vulnerability to depression among immigrants. The first row of the table shows that the association between migrant status and depression is always positive and statistically significant ( $p$-value<.001), meaning that immigrants systematically experience more depressive symptoms than their native counterparts even after controlling for a range of 
sociodemographic and socioeconomic characteristics $(\mathrm{OR}=1.67)$. The first column presents the results of a parsimonious model in which we only control for demographic factors, revealing that immigrants face 1.80 increased odds of depression compared to nonimmigrants. By controlling for physical health, the immigration coefficient decreases $(\mathrm{OR}=1.64)$, thus suggesting that the health advantage of immigrant groups significantly reduces depressive symptoms. On the contrary, the immigration coefficient increases $(\mathrm{OR}=1.83)$ after controlling for socioeconomic status (SES), thus highlighting the connection between poorer socioeconomic conditions, problems of financial strain and depressive symptoms among immigrants. The reduction of the immigration coefficient after controlling for social participation $(\mathrm{OR}=1.67)$ suggests that involvement in social activities (with the exception of religious organisation) clearly exerts a statistically positive effect, reducing depressive symptoms among immigrants. The immigration coefficient also decreases after controls for family social capital are added $(O R=1.78)$. The latter reflects two things. On the one hand, having children with noncompulsory education (upper secondary and tertiary) clearly reduces the odds of experiencing depressive symptoms above and beyond any other covariate, thus reflecting the possible causal relationship between the mental health of parents and children's education. On the other hand, regular contact of parents with their adult children also contributes significantly to reduce depressive symptoms, thus indicating the positive importance of intergenerational interaction for emotional status. Importantly, these associations do not disappear after including all confounders in the final model, thereby highlighting that adult children's educational attainment and parent-child contact have a differential effect on the mental health of older people.

[Table 5 about here]

In order to see whether the effect of children's education on depressive symptoms holds for immigrant groups, we run separate multilevel logistic regressions for immigrants and nonimmigrants. Table 6 reports the odds ratio of the final models with all the covariates. Although the results are not strictly comparable between the native and the foreign-born groups because of the different sets of parameters in the equations and the different number of cases, it seems clear that having highly educated children is mutually beneficial for both nonimmigrants and immigrants. Regular contact between parents and their adult children appears to be almost 
equally beneficial for both groups, thus indicating that frequent interaction between parents and children and the high level of education among adult children may be advantageous to parents' well-being throughout their later life. In other words, the effect of regular intergenerational contact does not negate the benefits of child's education but suggests additional mechanisms at work. This evidence supports the hypothesis that the educational level of children can be an added influence on their parent's mental health. Thus, it is reasonable to expect that, in addition to the emotional support usually derived from regular parent-child contact, the resources and knowledge from highly educated children would benefit the well-being of their parents as well as other aspects of their parents' lives.

[Table 6 about here]

The analysis also highlights the protective significant effect of social participation: Immigrants who are involved in sport or social club activities are less likely to experience depressive symptoms $(\mathrm{OR}=0.45)$. These findings are somewhat consistent with previous research highlighting the important role of active social participation of older adult migrants in the host society for their well-being (Aleksynska, 2011). Meanwhile, the measure on age at migration reveals that depression is higher among the foreign-born population who migrated between ages 16 and 49 compared to those who migrated before age $16(\mathrm{OR}=1.83)$. These findings suggest that even years after emigrating the immigration experience at certain ages is associated with an increased risk of depression, and therefore that acculturation may not be entirely protective. Our results reinforce findings from previous studies noting that the focus on acculturation ignores the sociohistorical contexts of migration, the racialization of contemporary immigrants, and the role these factors play in the differential social integration of immigrants (Viruell-Fuentes et al., 2012). It is also instructive to analyze the variable of geographical origin for immigrants, with results clearly indicating significant differences in terms of depressive symptoms between immigrants from Western Asia $(O R=2.55)$, Eastern Europe $(O R=1.99)$ and Northern Africa $(\mathrm{OR}=1.93)$ compared to immigrants from Western-Central Europe. Therefore, although immigrants share important commonalities that may influence their health later in life, it is evident that immigrant groups can be heterogeneous both within and across countries. 
[Table 7 about here]

Since the educational level of adult children is correlated with the educational level of their parents, Table 7 reports the odds of the models which allow us to examine whether the educational attainment of adult children has a stronger influence on the mental health of older migrants with lower education than their children (1). In order to see whether or not the effect of regular contact amplifies the relationship under consideration, we run the analysis for the subsample of respondents who stated having regular (i.e. daily or weekly) contact only (2). First, the results clearly demonstrate that having an adult child who has upper secondary/tertiary education reduces the odds of experiencing depressive symptoms among older migrants with primary/lower secondary $(\mathrm{OR}=0.50)$ or upper secondary/tertiary education $(\mathrm{OR}=0.44)$ compared to the reference group ( $p$-value<.05).

A similar relationship is found among nonimmigrants, whose odds of experiencing depressive symptoms also lessen if they have an adult child with at least upper secondary education. Although this advantage appears to be greatest for highly educated parents with highly educated children, the odds are sufficiently large among the group of less educated parents to suggest that higher levels of education among the younger generation may have an important influence on mental health. Second, the results from the analysis restricted only to respondents who have daily or weekly contact with their adult children indicate that the benefits of having highly educated children are even greater in family contexts with regular intergenerational interaction. For instance, immigrant parents with primary/lower secondary education or upper secondary/tertiary education whose adult children have tertiary education exhibit lower odds of experiencing depressive symptoms (between 0.50 and 0.38 respectively) compared to their counterpart immigrant parents whose adult children only have primary/lower secondary education. Similarly, nonimmigrant parents with primary/lower secondary education or upper secondary/tertiary education also benefit from having adult children with tertiary education, as demonstrated by the lower odds of depression among the first group $(\mathrm{OR}=0.61)$ and the second group $(\mathrm{OR}=0.60)$. These results illustrate that families that interact can influence one another in a multitude of ways, and these interactions are particularly beneficial among aging migrants in Europe, with mental health benefits for older migrants with well-educated adult children. 


\section{Discussion}

Despite the heterogeneity of immigrant groups both within and across countries in Europe, foreign-born populations share commonalities that may influence their (mental) health at older ages. This study shows that immigration is strongly associated with depressive symptoms among immigrants aged 50 and older even after controlling for demographic factors, physical health, socioeconomic status, social participation, and family social capital. While our results are consistent with the "healthy migrant effect", they also provide evidence that immigrants often live under socioeconomically disadvantaged conditions and as a result are more likely to experience depressive symptoms. Although our findings are in line with the social stress model (Berry, 1997), thus indicating that age at migration or "acculturation" may be an important factor to understand stress alleviation, the results also indicate that depressive symptoms are clearly mediated by the social context within which it occurs.

As noted in recent studies (Lopez-Class, Castro, \& Ramirez, 2011; Viruell-Fuentes et al., 2012), increasingly scholars have highlighted the limitations of the acculturation framework and proposed that the concept be broadened to take into consideration the impact of social contexts on cultural change, including social networks, neighbourhoods, and discrimination. In relation to social contexts and the availability of networks, the results from this study provide further new insights into the importance of family social capital, giving evidence that adult children's educational attainment has independent effects on the mental health of aging migrants after controlling for possible confounders. In addition, the results suggest that the education of the younger (second) generation of immigrants has an influence on the mental health of the older (first) generation of immigrants with different educational attainments themselves.

Moreover, the results indicate that regular intergenerational contact is associated with lower depressive symptoms among nonimmigrant and immigrant parents, thus suggesting that the existence of an opportunity structure (i.e. frequency of parent-child contact) is healthy enough to facilitate supportive exchanges (emotional and instrumental). Finally, the results also reveal that the benefits of having highly educated children in reducing depression increase if there is greater contact between parents and their adult children. Therefore, while greater contact of parents with 
their children may already lead to lower levels of depression, the qualitative aspects of the supporting relationship or the quality of children in terms of their educational attainment is, at least, equally important for the mental health of nonimmigrant and immigrant parents. These findings are consistent with the hypothesis that highly educated adult children may directly improve their parents' well-being through qualitative supportive exchanges and regular contact. Of course, it is also possible that highly educated children may make parents proud and untroubled; such status feelings have been suggested to influence mental health. This possibility would be consistent with our findings and warrants further investigation ${ }^{6}$.

While research on mental health typically emphasizes individual interventions, our study highlights that another way to influence the well-being of both older natives and aging foreignborn populations is through their adult children. The findings from this study are in accord with previous research and confirm the hypothesis that highly educated children improve their parent's (mental) health (Torssander, 2013; Sabater \& Graham, 2016). Therefore, the current study adds valuable new information on this association.

Some limitations are worth noting. First, our cross-sectional analysis limits causal inference. Second, our analysis does not account for the possible endogeneity due to family structure and immigration decision. The existence of an endogenous association between the goals of educating a child and the resources and attitudes of a parent that also promotes his or good health is a competing possibility. In this sense, we cannot rule out the possibility that the results are, at least partly, a statistical artefact as children's resources are likely to be correlated with family characteristics, and parents and children may also share many environmental and genetic circumstances (Lawlor \& Mishra, 2009). While family fixed-effects models adjusting for the characteristics that parents share with their children might be one way of overcoming this problem (Torssander, 2013), the details of generational differences per se cannot be investigated using SHARE data.

Third, the existence of a conflict at the time of migration may also affect the selectivity and the experience of some immigrant groups, leading to a higher level of stress or causing premature illhealth (Bohacek \& Myck, 2010). Although the sample size is sufficiently large to estimate an 
average effect with precision, immigrants were not specifically targeted in SHARE (i.e. the dataset does not include a "boost" sample of individuals belonging to ethnic or immigrant groups, and interviews were conducted in the official country language), thus increasing the chance of selection bias. Therefore, it may be expected that any biases from the second and third limitations are likely to lead to an underestimation of the depressive symptoms of immigrant groups.

Despite these cautions, the hypothesis advanced here is that the quality of children's resources, as reflected in their education, can lead to upward intergenerational transfers among migrants in Europe, with mental health benefits for older migrants with well-educated adult children. While the high rates of depression among immigrants are concerning, this study shows that explanations that are linked to the value of children's education for the mental health of aging migrants are clearly possible. More research is needed, however, to disentangle the causal nature of this relationship. If the education of children can have significant and far-reaching effects, these will not only be felt on the broader family unit but also across the societies in which the families live.

\section{Acknowledgements}

This paper uses data from SHARE Wave 1 (release 2.6.0, DOI: 10.6103/SHARE.w1.260). The SHARE data collection was funded primarily by the European Commission through its $5^{\text {th }}, 6^{\text {th }}$ and $7^{\text {th }}$ framework programmes (project numbers QLK6-CT-2001-00360, RII-CT-2006-062193, CIT5-CT-2005-028857, 211909, 227822 and 261982). Additional funding from the U.S. National Institute on Aging (U01 AG09740-13S2, P01 AG005842, P01 AG08291, P30 AG12815, R21 AG025169, Y1-AG-4553-01, IAG BSR06-11 and OGHA 04-064) as well as by various national sources is gratefully acknowledged (see http://www.share-project.org for a full list of funding institutions). The authors alone are responsible for the interpretation of the data. We would like to thank Nissa Finney, Georgina Lloyd, three anonymous reviewers and our editor for valuable comments on an earlier version of this manuscript. 


\section{References}

Albert, I., \& Ferring, D. (2013). Intergenerational relations. Bristol: Policy Press.

Alegria, M., Canino, G., Shrout, P. E., Woo, M., Duan, N., Vila, D., \& Meng, X. L. (2008). Prevalence of mental illness in immigrant and non-immigrant US Latino groups. The American Journal of Psychiatry, 165(3), 359-369.

Aleksynska, M. (2011). Civic Participation of Immigrants in Europe: Assimilation, Origin, and Destination Country Effects. European Journal of Political Economy, 27(3), 566-585.

Astone, N.M., Nathanson, C.A., Schoen, R., \& Kim, Y.J. (1999). Family demography, social theory, and investment in social capital. Population and Development Review, 25(1), 131.

Bandura, A. (1986). Social foundations of thought and action: A social cognitive theory. Englewood Cliffs: Prentice-Hall.

Barslund, M. (2012). Recent developments in selected education indicators and their relation to Europe 2020 targets. National Institute Economic Review, 220(1), R6-R16.

Bengtson, V. L. (2001). Beyond the nuclear family: The increasing importance of multigenerational bonds. Journal of Marriage and Family, 63(1), 1-16.

Berkman, L.F., \& Glass, T. (2000). Social integration, social networks, social support, and health. In Berkman LF and Kawachi I (Eds.). Social Epidemiology (pp. 137-173). New York: Oxford University Press.

Berry, J. W. (1997). Immigration, acculturation, and adaptation. Applied Psychology, 46(1), 534.

Blazer, D. G. (2003). Depression in late life: review and commentary. Journals of Gerontology Series A, 58(3), 249-265.

Bohacek, R. and Myck, M. (2010). Persecution in Central Europe and Its Consequences on the Lives of SHARE Respondents, MEA Mannheim Research Institute for the Economics of Aging 233 Print.

Börsch-Supan, A. (2013). Survey of Health, Ageing and Retirement in Europe (SHARE) Wave 1. Release version: 2.6.0. SHARE-ERIC. Data set. DOI: 10.6103/SHARE.w1.260

Börsch-Supan, A., \& Jürges H. (Eds.). (2005). The Survey of Health, Ageing and Retirement in Europe - Methodology. Mannheim: Mannheim Research Institute for the Economics of Aging (MEA). 
Börsch-Supan, A., Brugiavini A., Jürges H., Mackenbach J., Siegrist J., \& Weber G. (2005). Health, ageing and retirement in Europe - First results from the Survey of Health, Ageing and Retirement in Europe. Mannheim: Mannheim Research Institute for the Economics of Aging (MEA).

Brandt, M., Haberkern, K., \& Szydlik, M. (2009). Intergenerational help and care in Europe. European Sociological Review, 25(5), 585-601.

Buber, I., \& Engelhardt, H. (2008). Children's impact on the mental health of their older mothers and fathers: findings from the Survey of Health, Ageing and Retirement in Europe. European Journal of Ageing, 5(1), 31-45.

Burnam, M. A., Hough, R. L., Karno, M., Escobar, J. I., \& Telles, C. A. (1987). Acculturation and lifetime prevalence of psychiatric disorders among Mexican Americans in Los Angeles. Journal of Health and Social Behavior, 28(1), 89-102.

Carta, M. G., Bernal, M., Hardoy, M. C., \& Haro-Abad, J. M. (2005). Migration and mental health in Europe. Clinical Practice and Epidemiology in Mental Health, 1(1), 13.

Christiansen, S. G. (2014). The impact of children's sex composition on parents' mortality. BMC public health, 14(1), 989.

Cutler, D.M., \& Lleras-Muney A. (2010). Understanding differences in health behaviors by education. Journal of Health Economics, 29(1), 1-28.

Dewey, M. E. \& Prince, M. J. (2005). Mental Health. In A. Börsch-Supan \& H. Jürges (Eds.). Health, Ageing and Retirement in Europe - First Results from the Survey of Health, Ageing and Retirement in Europe (pp. 108-117). Mannheim, MEA Eigenverlag.

Friedman, E., \& Mare, R. (2014). The Schooling of Offspring and the Survival of Parents. Demography, 51(4), 1271-1293.

Gong, F., Xu, J., Fujishiro, K., \& Takeuchi, D. T. (2011). A life course perspective on migration and mental health among Asian immigrants: The role of human agency. Social Science \& Medicine, 73(11), 1618-1626.

Hank, K. (2007). Proximity and contacts between older parents and their children: A European comparison. Journal of Marriage and Family, 69(1), 157-173.

House, J. S., Kessler, R. C., Herzog, A. R., Mero, R. P., Kinney, A. M., \& Breslow, M. J. (1990). Age, socioeconomic status, and health. The Milbank Quarterly, 68(3), 383-411. 
Hunkler, C., Kneip, T., Sand, G., \& Schuth, M. (2015). Growing Old Abroad: Social and Material Deprivation among First- and Second Generation Migrants in Europe. In A. Börsch-Supan, T. Kneip, H. Litwin, M. Myck, \& G. Weber. Ageing in EuropeSupporting Policies for an Inclusive Society (pp. 199-208). Berlin: De Gruyer.

Ladin, K., \& Reinhold, S. (2013). Mental health of aging immigrants and native-born men across 11 European countries. The Journals of Gerontology Series B: Psychological Sciences and Social Sciences, 68(2), 298-309.

Lawlor, D.A., \& Mishra, G.D. (2009). Why family matters: an introduction. In D.A. Lawlor \& G.D. Mishra (Eds.). Family Matters (pp. 1-9). Oxford: Oxford University Press.

Lehtinen, V., Sohlman, B., \& Kovess-Masfety, V. (2005). Level of positive mental health in the European Union: Results from the Eurobarometer 2002 survey. Clinical Practice and Epidemiology in Mental Health, 1(1), 9.

Lopez-Class, M., Castro, F. G., \& Ramirez, A. G. (2011). Conceptions of acculturation: a review and statement of critical issues. Social Science \& Medicine, 72(9), 1555-1562.

Mastekaasa, A. (1992). Marriage and psychological well-being: Some evidence on selection into marriage. Journal of Marriage and the Family, 54(4), 901-911.

McGarry, K. (1998). Caring for the Elderly: The Role of Adult Children. In D.A. Wise (Ed.). Inquiries in the Economics of Aging (pp. 133-163). Chicago: University of Chicago Press.

Mirowsky, J., \& Ross, C. E. (1980). Minority status, ethnic culture, and distress: A comparison of Blacks, Whites, Mexicans, and Mexican Americans. American Journal of Sociology, 86(3), 479-495.

Mirowsky, J., Ross, C. E., \& Reynolds, J. (2000). Links between social status and health status. Handbook of medical sociology, 5, 47-67.

Missinne, S. \& Bracke, P. (2012). Depressive symptoms among immigrants and ethnic minorities: a population based study in 23 European countries. Social Psychiatry and Psychiatric Epidemiology 47(1), 97-109.

Nazroo, J.Y. (2003). The Structuring of Ethnic Inequalities in Health: Economic Position, Racial Discrimination, and Racism, American Journal of Public Health, 93(2), 277-284.

Nazroo, J.Y. (2006). Ethnicity and Old Age. In J.A. Vincent, C. Phillipson, \& M. Downs (Eds.). The Futures of Old Age. London: Sage. 
Prince, M. J., Reischies, F., Beekman, A. T. F., Fuhrer, R., Jonker, C., Kivela, S.-L., Lawlor, B. A., Lobo, A., Magnusson, H., Fichter, M., van Oyen, H., Roelands, M., Skoog, I., Turrina, C., \& Copeland, J. R. M. (1999). Development of the EURO-D scale - a European Union initiative to compare symptoms of depression in 14 European centres. The British Journal of Psychiatry 174(4), 330-338.

Ross, C. E., \& Mirowsky, J. (1989). Explaining the social patterns of depression: control and problem solving--or support and talking?. Journal of Health and Social Behavior, 30(2), 206-219.

Ross, C. E., \& Mirowsky, J. (2006). Sex differences in the effect of education on depression: resource multiplication or resource substitution?. Social Science \& Medicine, 63(5), $1400-1413$.

Sabater, A., \& Graham, E. (forthcoming). Children's Education and Parents' Longevity: Evidence for Upward Intergenerational Health Transfers in Europe.

Schwarzer, R. \& Schulz, U. (2012). Stressful life events. Handbook of psychology, 2, 25-49.

Seeman, T.E. (2000). Health promoting effects of friends and family on health outcomes in older adults. American Journal of Health Promotion, 14(6), 362-370.

Silverstein, M., Gans, D., \& Yang, F.M. (2006). Intergenerational support to aging parents - The role of norms and needs. Journal of Family Issues, 27(8), 1068-1084.

Stronks, K. (2003). Public Health Research among Immigrant Populations: Still a Long Way to Go. European Journal of Epidemiology, 18(9), 841-842.

Thornicroft, G., Brohan, E., Kassam, A., \& Lewis-Holmes, E. (2008). Reducing stigma and discrimination: Candidate interventions. International Journal of Mental Health Systems, 2(1), 1 .

Tinghög, P., Hemmingsson, T., \& Lundberg, I. (2007). To what extent may the association between immigrant status and mental illness be explained by socioeconomic factors? Social Psychiatry and Psychiatric Epidemiology, 42(12), 990-996.

Torssander, J. (2013). From Child to Parent? The Significance of Children's Education for Their Parents' Longevity. Demography, 50(2), 637-659.

Uhlenberg, P., \& Riley, M.W. (2000). Essays on Age Integration. The Gerontologist, 40, 261308. 
Viruell-Fuentes, E. A., Miranda, P. Y., \& Abdulrahim, S. (2012). More than culture: structural racism, intersectionality theory, and immigrant health. Social Science \& Medicine, 75(12), 2099-2106.

Warnes, A.M., \& Williams, A. (2006). Older migrants in Europe: a new focus for migration studies. Journal of Ethnic and Migration Studies, 32(8), 1257-1281.

Wheaton, B. (1980). The sociogenesis of psychological disorder: An attributional theory. Journal of health and Social Behavior, 21(2), 100-124. 
Table 1. Distribution of Non-immigrants and Immigrants Across 'Old' Immigration Countries from SHARE (2004)

\begin{tabular}{lccl}
\hline & \multicolumn{3}{c}{ Population } \\
\cline { 2 - 4 } Country & $\begin{array}{c}\text { Non- } \\
\text { immigrants }\end{array}$ & Immigrants & Total \\
\cline { 2 - 4 } & $(\%)$ & $(\%)$ & \multicolumn{1}{c}{$N$} \\
\hline Austria & 91.6 & 8.4 & 913 \\
Belgium & 92.9 & 7.1 & 1,911 \\
Denmark & 96.1 & 3.9 & 945 \\
France & 86.5 & 13.5 & 1,552 \\
Germany & 80.4 & 19.6 & 1,468 \\
Netherlands & 94.2 & 5.8 & 1,475 \\
Sweden & 92.8 & 7.2 & 1,792 \\
Switzerland & 85.3 & 14.7 & 462 \\
Total & 9,489 & 1,029 & 10,518 \\
\hline
\end{tabular}


Table 2. Distribution of Immigrants Across Main Geographical Origins from SHARE (2004)

\begin{tabular}{|c|c|c|}
\hline & \multicolumn{2}{|c|}{ Immigrants } \\
\hline & \multicolumn{2}{|c|}{$\begin{array}{c}\text { Geographical } \\
\text { origin } \\
\end{array}$} \\
\hline & $(\%)$ & $N$ \\
\hline Western-Central Europe & 32.8 & 338 \\
\hline Southern Europe & 19.8 & 204 \\
\hline Eastern Europe & 16.6 & 171 \\
\hline Northern Africa & 9.7 & 100 \\
\hline Northern Europe & 8.8 & 91 \\
\hline Western Asia & 8.0 & 82 \\
\hline Other & 4.2 & 43 \\
\hline Total & 100.0 & 1,029 \\
\hline
\end{tabular}


Table 3. Distribution of Key Variables for Non-immigrants and Immigrants from SHARE (2004). Percentages

\begin{tabular}{|c|c|c|c|}
\hline & & $\begin{array}{c}\text { Non- } \\
\text { immigrants } \\
(\mathrm{n}=9,489) \\
\end{array}$ & $\begin{array}{l}\text { Immigrants } \\
(\mathrm{n}=1,029)\end{array}$ \\
\hline \multirow[t]{2}{*}{ Age } & (mean) & 66.22 & 66.52 \\
\hline & $(\mathrm{SD})$ & 10.14 & 10.10 \\
\hline \multirow[t]{2}{*}{ Age at migration } & (mean) & & 22.46 \\
\hline & (SD) & & 15.45 \\
\hline \multirow[t]{3}{*}{ Age at migration (groups) } & $0-15$ & & 33.40 \\
\hline & $16-49$ & & 59.10 \\
\hline & $50+$ & & 7.50 \\
\hline \multirow[t]{2}{*}{ Citizenship } & no & 0.16 & 25.36 \\
\hline & yes & 99.84 & 74.64 \\
\hline \multirow[t]{2}{*}{ Gender } & Male & 46.31 & 45.00 \\
\hline & Female & 53.69 & 55.00 \\
\hline \multirow[t]{2}{*}{ Chronic diseases } & less than 2 & 58.12 & 52.43 \\
\hline & 2 or more & 41.88 & 47.57 \\
\hline \multirow[t]{2}{*}{ ADL limitations } & no & 84.45 & 81.34 \\
\hline & yes & 15.55 & 18.66 \\
\hline \multirow[t]{2}{*}{ Own's education } & compulsory level & 44.84 & 44.10 \\
\hline & non-compulsory level & 55.16 & 55.90 \\
\hline \multirow[t]{2}{*}{ Household income (Euros) } & (mean) & 44,166 & 39,353 \\
\hline & $(\mathrm{SD})$ & 41,127 & 43,591 \\
\hline \multirow[t]{2}{*}{ Involved in charity } & no & 82.88 & 91.58 \\
\hline & yes & 17.12 & 8.42 \\
\hline \multirow[t]{2}{*}{ Involved in education or training } & no & 91.46 & 95.10 \\
\hline & yes & 8.54 & 4.90 \\
\hline \multirow[t]{2}{*}{ Involved in sport or social club } & no & 73.90 & 84.43 \\
\hline & yes & 26.10 & 15.57 \\
\hline \multirow[t]{2}{*}{ Involved in religious organisation } & no & 90.46 & 91.38 \\
\hline & yes & 9.54 & 8.62 \\
\hline \multirow[t]{2}{*}{ Involved in political/community org } & no & 94.76 & 97.45 \\
\hline & yes & 5.24 & 2.55 \\
\hline
\end{tabular}


Table 3 (cont.)

\begin{tabular}{llcc}
\hline & & con- & \\
& & $\begin{array}{c}\text { Non } \\
\text { immigrants } \\
(\mathrm{n}=9,489)\end{array}$ & $\begin{array}{c}\text { Immigrants } \\
(\mathrm{n}=1,029)\end{array}$ \\
\hline Marital status & Married-partnership & 66.73 & 62.39 \\
& Single & 33.27 & 37.61 \\
Partner's education & compulsory level & 40.68 & 43.00 \\
& non-compulsory level & 59.32 & 57.00 \\
Number of children & (mean) & 2.47 & 2.61 \\
& (SD) & 1.28 & 1.48 \\
Children's education & compulsory level & 12.67 & 14.77 \\
Regular contact with children & non-compulsory level & 87.33 & 85.23 \\
& no & 21.31 & 24.39 \\
& yes & 78.69 & 75.61 \\
\hline
\end{tabular}


Table 4. Adult Children's Educational Attainment by Parent's Own Attainment (Non-immigrant and Immigrants). Percentages

\begin{tabular}{|c|c|c|c|c|c|c|c|c|}
\hline \multirow[b]{3}{*}{$\begin{array}{l}\text { Respondent's } \\
\text { Education }\end{array}$} & \multicolumn{4}{|c|}{ Non-immigrants } & \multicolumn{4}{|c|}{ Immigrants } \\
\hline & \multicolumn{4}{|c|}{ Proportion of children with: } & \multicolumn{4}{|c|}{ Proportion of children with: } \\
\hline & Primary & $\begin{array}{c}\text { Lower } \\
\text { secor }\end{array}$ & $\begin{array}{l}\text { Upper } \\
\text { dary }\end{array}$ & Tertiary & Primary & $\begin{array}{c}\text { Lower } \\
\text { secor }\end{array}$ & $\begin{array}{l}\text { Upper } \\
\text { dary }\end{array}$ & Tertiary \\
\hline Primary & 6.5 & 21.6 & 50.5 & 21.4 & 10.9 & 22.2 & 47.3 & 19.6 \\
\hline Lower secondary & 0.8 & 15.1 & 52.7 & 31.5 & 1.2 & 14.5 & 55.2 & 29.1 \\
\hline Upper secondary & 0.3 & 5.1 & 52.9 & 41.7 & 0.6 & 4.4 & 53.7 & 41.4 \\
\hline Tertiary & 0.5 & 2.2 & 32.7 & 64.7 & 0.9 & 4.1 & 29.8 & 65.1 \\
\hline
\end{tabular}


Table 5. Odds Ratio Depicting the Relationship Between Immigrant Status and Depression Through Five Explanatory Pathways

\begin{tabular}{|c|c|c|c|c|c|c|}
\hline & $\begin{array}{r}\text { Demographic } \\
\text { factors }\end{array}$ & $\begin{array}{r}\text { Phsysical } \\
\text { health }\end{array}$ & $\begin{array}{r}\text { Socio-economic } \\
\text { status }\end{array}$ & $\begin{array}{r}\text { Social } \\
\text { participation }\end{array}$ & $\begin{array}{r}\text { Family } \\
\text { support }\end{array}$ & $\begin{array}{r}\text { Complete } \\
\text { model }\end{array}$ \\
\hline \multirow[t]{2}{*}{ Immigrant } & $1.80 * * *$ & $1.64 * * *$ & $1.83 * * *$ & $1.67 * * *$ & $1.78 * * *$ & $1.67 * * *$ \\
\hline & $(0.131)$ & $(0.124)$ & $(0.157)$ & $(0.124)$ & $(0.131)$ & $(0.152)$ \\
\hline \multirow[t]{2}{*}{ Age } & $0.85 * * *$ & $0.86 * * *$ & $0.85 * * *$ & $0.85 * * *$ & $0.87 * * *$ & $0.90 * *$ \\
\hline & $(0.023)$ & $(0.025)$ & $(0.028)$ & $(0.024)$ & $(0.025)$ & $(0.031)$ \\
\hline \multirow[t]{2}{*}{ Age squared } & $1.00 * * *$ & $1.00 * * *$ & $1.00 * * *$ & $1.00 * * *$ & $1.00 * * *$ & $1.00 * *$ \\
\hline & $(0.000)$ & $(0.000)$ & $(0.000)$ & $(0.000)$ & $(0.000)$ & $(0.000)$ \\
\hline \multirow[t]{2}{*}{ Female } & $2.35 * * *$ & $2.09 * * *$ & $1.98 * * *$ & $2.30 * * *$ & $2.41 * * *$ & $1.94 * * *$ \\
\hline & $(0.118)$ & $(0.108)$ & $(0.125)$ & $(0.116)$ & $(0.123)$ & $(0.129)$ \\
\hline \multirow[t]{2}{*}{2 or more chronic diseases } & & $1.82 * * *$ & & & & $1.74 * * *$ \\
\hline & & $(0.094)$ & & & & $(0.108)$ \\
\hline \multirow[t]{2}{*}{ ADL limitations } & & $3.24 * * *$ & & & & $3.26 * * *$ \\
\hline & & $(0.203)$ & & & & $(0.251)$ \\
\hline \multirow[t]{2}{*}{ Own's education - post-compulsory } & & & $0.81 * * *$ & & & 0.95 \\
\hline & & & $(0.053)$ & & & $(0.067)$ \\
\hline \multirow[t]{2}{*}{ Single } & & & $1.42 * * *$ & & & $1.31 * * *$ \\
\hline & & & $(0.095)$ & & & $(0.093)$ \\
\hline \multirow[t]{2}{*}{ Partner's education - post-compulsory } & & & 0.95 & & & 1.084 \\
\hline & & & $(0.061)$ & & & $(0.076)$ \\
\hline \multirow[t]{2}{*}{ Household income } & & & $0.78 * * *$ & & & $0.84 *$ \\
\hline & & & $(0.056)$ & & & $(0.062)$ \\
\hline
\end{tabular}


Table 5 (cont.)

\begin{tabular}{|c|c|c|c|c|c|c|}
\hline & $\begin{array}{r}\text { Demographic } \\
\text { factors } \\
\end{array}$ & $\begin{array}{r}\text { Phsysical } \\
\text { health } \\
\end{array}$ & $\begin{array}{r}\text { Socio-economic } \\
\text { status } \\
\end{array}$ & $\begin{array}{r}\text { Social } \\
\text { participation } \\
\end{array}$ & $\begin{array}{r}\text { Family } \\
\text { support } \\
\end{array}$ & $\begin{array}{r}\text { Complete } \\
\text { model } \\
\end{array}$ \\
\hline \multirow[t]{2}{*}{ Involved in charity } & & & & $0.81 * *$ & & $0.84 \dagger$ \\
\hline & & & & $(0.061)$ & & $(0.078)$ \\
\hline \multirow[t]{2}{*}{ Involved in education or training } & & & & $0.76 * *$ & & 0.96 \\
\hline & & & & $(0.077)$ & & $(0.116)$ \\
\hline \multirow[t]{2}{*}{ Involved in sport or social club } & & & & $0.68 * * *$ & & $0.78 * * *$ \\
\hline & & & & $(0.042)$ & & $(0.059)$ \\
\hline \multirow[t]{2}{*}{ Involved in religious organisation } & & & & 0.88 & & 0.93 \\
\hline & & & & $(0.079)$ & & $(0.097)$ \\
\hline \multirow[t]{2}{*}{ Involved in political/community org } & & & & $0.70 * *$ & & 0.78 \\
\hline & & & & $(0.096)$ & & $(0.138)$ \\
\hline \multirow[t]{2}{*}{ Number of children } & & & & & 1.00 & 0.98 \\
\hline & & & & & $(0.018)$ & $(0.023)$ \\
\hline \multirow[t]{2}{*}{ Children's education - post-compulsory } & & & & & $0.54 * * *$ & $0.61 * * *$ \\
\hline & & & & & $(0.036)$ & $(0.055)$ \\
\hline \multirow[t]{2}{*}{ Regular contact with children } & & & & & $0.69 * * *$ & $0.71 * * *$ \\
\hline & & & & & $(0.039)$ & $(0.050)$ \\
\hline$A I C$ & 10799.58 & 10255.54 & 7733.31 & 10671.22 & 10621.65 & 7211.31 \\
\hline$B I C$ & 10843.14 & 10313.63 & 7803.09 & 10751.05 & 10694.22 & 7357.71 \\
\hline$L L V$ & -5393.79 & -5119.77 & -3856.65 & -5324.61 & -5300.83 & -3584.65 \\
\hline
\end{tabular}

Note. $\uparrow \mathrm{p}<.1 ; * \mathrm{p}<.05 ; * * \mathrm{p}<.01 ; * * * \mathrm{p}<.001$. Reference groups (non-immigrant, male, less than 2 chronic diseases, without ADL limitations, respondent's compulsory education, not involved in charity, not involved in education or training, not involved in sport or social club, not involved in religious organisation, not involved in political/community organisation, children's compulsory education, without regular contact with children). Measures of the relative quality of statistical models: Akaike/Bayesian Information Criterion (AIC/BIC) and Log-Likelihood Value (LLV). 
Table 6. Odds Ratio Depicting the Relationship Between Depression and Explanatory Pathways for Nonimmigrants and Immigrants

\begin{tabular}{|c|c|c|}
\hline & $\begin{array}{c}\text { Non- } \\
\text { immigrants }\end{array}$ & Immigrants \\
\hline \multirow[t]{2}{*}{ Age } & $0.90 * *$ & 0.99 \\
\hline & $(0.032)$ & $(0.116)$ \\
\hline \multirow[t]{2}{*}{ Age squared } & $1.00 * *$ & 1.00 \\
\hline & $(0.000)$ & $(0.001)$ \\
\hline \multirow[t]{2}{*}{ Female } & $1.95 * * *$ & $2.23 * * *$ \\
\hline & $(0.138)$ & $(0.453)$ \\
\hline \multirow[t]{2}{*}{2 or more chronic diseases } & $1.75 * * *$ & $1.62 * *$ \\
\hline & $(0.117)$ & $(0.301)$ \\
\hline \multirow[t]{2}{*}{ ADL limitations } & $3.26 * * *$ & $3.55 * * *$ \\
\hline & $(0.266)$ & $(0.840)$ \\
\hline \multirow[t]{2}{*}{ Own's education - post-compulsory } & 0.96 & 0.91 \\
\hline & $(0.073)$ & $(0.195)$ \\
\hline \multirow[t]{2}{*}{ Single } & $1.34 * * *$ & 1.13 \\
\hline & $(0.102)$ & $(0.242)$ \\
\hline \multirow[t]{2}{*}{ Partner's education - post-compulsory } & 1.03 & 1.01 \\
\hline & $(0.077)$ & $(0.362)$ \\
\hline \multirow[t]{2}{*}{ Household income } & $0.81 * *$ & 0.98 \\
\hline & $(0.066)$ & $(0.199)$ \\
\hline \multirow[t]{2}{*}{ Involved in charity } & $0.85 \dagger$ & 0.88 \\
\hline & $(0.082)$ & $(0.292)$ \\
\hline \multirow[t]{2}{*}{ Involved in education or training } & 0.97 & 0.79 \\
\hline & $(0.122)$ & $(0.345)$ \\
\hline \multirow[t]{2}{*}{ Involved in sport or social club } & $0.81 * *$ & $0.45 * *$ \\
\hline & $(0.064)$ & $(0.126)$ \\
\hline \multirow[t]{2}{*}{ Involved in religious organisation } & 0.92 & 0.87 \\
\hline & $(0.104)$ & $(0.256)$ \\
\hline \multirow[t]{2}{*}{ Involved in political/community org } & 0.76 & 0.83 \\
\hline & $(0.140)$ & $(0.636)$ \\
\hline
\end{tabular}


Table 6 (cont.)

\begin{tabular}{|c|c|c|}
\hline & $\begin{array}{c}\text { Non- } \\
\text { immigrants }\end{array}$ & Immigrants \\
\hline \multirow[t]{2}{*}{ Number of children } & 0.97 & 1.06 \\
\hline & $(0.025)$ & $(0.066)$ \\
\hline \multirow[t]{2}{*}{ Children's education - post-compulsory } & $0.65 * * *$ & $0.46 * *$ \\
\hline & $(0.062)$ & $(0.125)$ \\
\hline \multirow[t]{2}{*}{ Regular contact with children } & $0.73 * * *$ & $0.54 * *$ \\
\hline & $(0.055)$ & $(0.108)$ \\
\hline \multirow[t]{2}{*}{ Without citizenship of host country } & & 1.60 \\
\hline & & $(0.399)$ \\
\hline \multicolumn{3}{|l|}{ Age at migration } \\
\hline \multirow[t]{2}{*}{$16-49$ years } & & $1.83 * *$ \\
\hline & & $(0.382)$ \\
\hline \multirow[t]{2}{*}{$50+$ years } & & 0.94 \\
\hline & & $(0.357)$ \\
\hline \multicolumn{3}{|l|}{ Geographical origin } \\
\hline \multirow[t]{2}{*}{ Southern Europe } & & 1.17 \\
\hline & & $(0.288)$ \\
\hline \multirow[t]{2}{*}{ Eastern Europe } & & $1.99 *$ \\
\hline & & $(0.604)$ \\
\hline \multirow[t]{2}{*}{ Northern Africa } & & $1.93 \dagger$ \\
\hline & & $(0.721)$ \\
\hline \multirow[t]{2}{*}{ Northern Europe } & & 1.13 \\
\hline & & $(0.368)$ \\
\hline \multirow[t]{2}{*}{ Western Asia } & & $2.55 * *$ \\
\hline & & $(0.865)$ \\
\hline \multirow[t]{2}{*}{ Other } & & 0.90 \\
\hline & & $(0.423)$ \\
\hline$A I C$ & 6362.62 & 864.47 \\
\hline$B I C$ & 6500.02 & 998.83 \\
\hline$L L V$ & -3161.31 & -403.23 \\
\hline
\end{tabular}


Note. $\uparrow \mathrm{p}<.1 ; * \mathrm{p}<.05 ; * * \mathrm{p}<.01 ; * * * \mathrm{p}<.001$. Reference groups (non-immigrant, male, less than 2 chronic diseases, without ADL limitations, respondent's compulsory education, not involved in charity, not involved in education or training, not involved in sport or social club, not involved in religious organisation, not involved in political/community organisation, children's compulsory education, without regular contact with children, with citizenship of host country, age at migration 0-15 years, and Western-Central Europe). Measures of the relative quality of statistical models: Akaike/Bayesian Information Criterion (AIC/BIC) and Log-Likelihood Value (LLV). 
Table 7. Odds Ratio Depicting the Relationship Between Depression and Family Social Capital (with Educational Differences for Parents and Their Adult Children) for Non-immigrants and Immigrants

\begin{tabular}{|c|c|c|c|c|c|}
\hline & & $\begin{array}{c}\text { Non- } \\
\text { immigrants (1) }\end{array}$ & $\begin{array}{c}\text { Non- } \\
\text { immigrants (2) }\end{array}$ & Immigrants (1) & Immigrants (2) \\
\hline Parents' education & Children's education & & & & \\
\hline Primary or lower secondary & Primary or lower secondary & 1.000 & 1.000 & 1.000 & 1.000 \\
\hline Primary or lower secondary & Upper secondary and higher & $\begin{array}{l}0.658 * * * \\
(0.073)\end{array}$ & $\begin{array}{l}0.619 \text { *** } \\
(0.080)\end{array}$ & $\begin{array}{c}0.506 * \\
(0.165)\end{array}$ & $\begin{array}{l}0.502 \dagger \\
(0.231)\end{array}$ \\
\hline Upper secondary and higher & Primary or lower secondary & $\begin{array}{r}0.977 \\
(0.196)\end{array}$ & $\begin{array}{r}0.749 \\
(0.197)\end{array}$ & $\begin{array}{r}1.241 \\
(0.704)\end{array}$ & $\begin{array}{r}0.632 \\
(0.511)\end{array}$ \\
\hline Upper secondary or tertiary & Upper secondary and higher & $\begin{array}{l}0.617 \text { *** } \\
(0.075)\end{array}$ & $\begin{array}{l}0.601 \text { *** } \\
(0.089)\end{array}$ & $\begin{array}{l}0.443 * \\
(0.152)\end{array}$ & $\begin{array}{l}0.383 * \\
(0.174)\end{array}$ \\
\hline$A I C$ & & 6361.42 & 4837.37 & 866.11 & 620.24 \\
\hline$B I C$ & & 6505.69 & 4969.98 & 1005.11 & 746.41 \\
\hline$L L V$ & & -3159.71 & -2398.69 & -403.05 & -281.12 \\
\hline
\end{tabular}

Note. $\uparrow \mathrm{p}<.1 ; * \mathrm{p}<.05 ; * * \mathrm{p}<.01 ; * * * \mathrm{p}<.001$. Reference group is parents with primary or lower secondary and children with primary or lower secondary. (1) Full sample, and (2) subsample of respondents (7,467 non-immigrants and 778 immigrants) who stated having regular (i.e. daily or weekly) contact only. Measures of the relative quality of statistical models: Akaike/Bayesian Information Criterion (AIC/BIC) and Log-Likelihood Value (LLV). 


\section{Footnotes}

${ }^{1}$ In the European Union, the share of persons aged 25 to 34 years with tertiary education has increased from 23\% to 33\% between 2000 and 2010 (Barslund, 2012).

2 The consequences of the independence of Estonia and the split of Czechoslovakia into the Czech Republic and Slovakia have resulted in high proportion of migrants when the majority did not even have to move to technically be classified as a migrant (Hunkler et al., 2015).

${ }^{3}$ It is important to note that SHARE only allows indications of depression as it does not involve medical diagnosis.

${ }^{4}$ Household income is defined by annual earnings by all household members. Household wealth (total net worth) consists of the sum of all financial (net stock value, mutual funds, bonds and savings) and housing wealth (value of primary residence net of mortgage, other real estate value, own business share and owned cars) minus liabilities.

${ }^{5}$ For greater detail, we employ four categories: levels 0-1 (pre-primary and primary), 2 (lower secondary), 3 and 4 (upper secondary and post-secondary non-tertiary) and 5-6 (first and second stages of tertiary education) of the ISCED (international standard classification of education).

${ }^{6}$ We thank the editor for bringing this to our attention. 